\title{
Uma rede de ação para formação de jovens
}

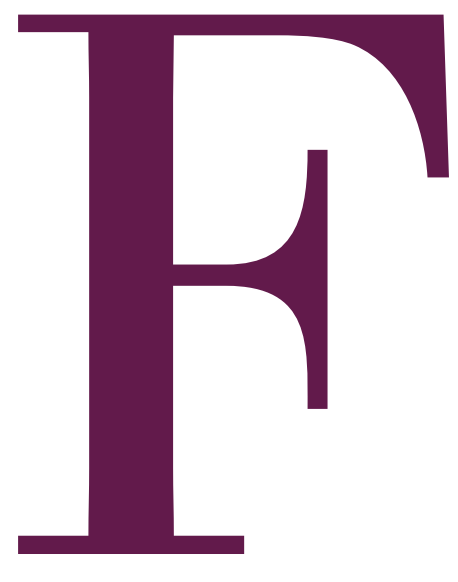

alamos hoje, e muito, sobre parcerias na condução de projetos sociais. Essa vocalização social em torno de termos como ação em rede, cooperação, articulação... expressa um valor sociopolítico na condução de ações públicas.

Enfatizamos nesta revista uma formação de jovens tendo como cenários Cidade, Cultura e Tecnologia.

Nessa perspectiva, a formação fomenta a inserção dos jovens em espaços e fatos desconhecidos da cidade, propiciando a ampliação de repertórios culturais, o usufruto de direitos e o acesso a saberes e culturas em movimento nos cenários urbanos.

Essa lógica programática só é exeqüível com o envolvimento de múltiplos parceiros comprometidos com a oferta conjunta de oportunidades de aprendizagem que componham com o tripé Cidade, Cultura e Tecnologia.

Essas oportunidades estão espalhadas pela cidade, descentralizadas em agências governamentais, empresas públicas, empresas privadas, organizações da sociedade civil, instituições representantes do campo das artes, do mundo do trabalho e da produção de tecnologias.

Assim, uma real oferta de formação para juventudes urbanas só é sustentável numa perspectiva de ação pública em rede e na necessidade de legitimidade de suporte institucional e político às ações de intervenção junto ao público juvenil.

\section{Mas, o que são redes?}

A rede sugere uma teia de vínculos, relações e ações entre indivíduos e organizações. As redes se tecem e se dissolvem continuamente em todos os campos da vida so-

MARIA DO CARMO BRANT DE CARVALHO é coordenadora Geral do Cenpec - Centro de Estudos e Pesquisas em Educação, Cultura e Ação Comunitária e ex-professora do Programa de Estudos Pós-Graduados em Serviço Social da PUC-SP. 
cietária. Elas estão presentes na vida cotidiana - nas relações de parentesco, nas relações de vizinhança, nas relações comunitárias -, no mundo dos negócios, na vida pública e se realimentam e se reconstroem internamente. As redes podem assumir características mais duradouras ou efêmeras, vínculos mais densos ou mais tênues, simples ou complexos.

No passado, o conceito de rede já era utilizado na gestão dos serviços sociais públicos. Acompanhava o modelo de gestão da época, ou seja, um modelo centralizado, setorial e caracterizado pela hierarquização e padronização na oferta de serviços. Falávamos em rede escolar, rede de unidades básicas de saúde, rede hospitalar, todas elas, no geral, subordinadas a uma organizaçãomãe. A rede era então percebida como uma cadeia de serviços similares tal qual na gestão empresarial.

O termo rede não é novo, mas na vida contemporânea expressa um novo conceito. Esse novo conceito de rede usufruiu em sua formulação dos avanços tecnológicos e, ao mesmo tempo, pode ser expresso no campo legal, demandando intersetorialidade às políticas públicas.

Os avanços tecnológicos, digitais e de linguagens multimídias agilizam e ampliam os fluxos de informação e comunicação entre seus integrantes. Tais ferramentas potencializam e democratizam o universo das redes. Outra novidade é a mudança de perspectiva, antes uma estrutura hierárquica vertical, hoje uma estrutura flexível e horizontal; antes uma ligação entre iguais, hoje uma relação entre diferentes.

Atualmente, a utilização do conceito de rede ajuda a caracterizar a sociedade contemporânea e os novos modelos de gestão dos negócios privados ou públicos, em escala local ou global. Para alguns estudiosos, a sociedade contemporânea conforma-se como sociedade em rede (Manuel Castells, 1998; Ruth Cardoso, 2001; G.Dupas, 2003). Como bem afirma Cardoso,

não desapareceu a velha sociedade civil, mas tornou-se mais complexa a dinâmica de apresentação dos interesses coletivos.

Essa complexidade decorre do fato de que a sociedade de hoje se apresenta tecida pela fragmentação de interesses e espaços de ação política. Não são mais as grandes narrativas e utopias coletivas que agregam, mas sim os micro-discursos identitários. Daí a imagem de uma sociedade multifacetada.

A sociedade se fragmentou em espaços de ação política que não mais se confundem com as formas tradi- cionais de representação, mas que podem formar redes que conectam, solidariamente, os vários núcleos que as formam. E não se pense que esses núcleos têm perspectivas e objetivos não-conflitivos. A grande característica dessas sociedades é a diversidade de pontos de vista que acolhem, e é legítima a manifestação dessas posições" (Cardoso. 2001).

Dupas (2003, p.17) nos lembra que

(...) passamos de uma sociedade política a uma sociedade organizacional, entendida essa última como uma sociedade de gestão sistêmica e tecnocrática que pretende legitimar os direitos da pessoa. ${ }^{1}$

A fruição da ação em rede provoca uma retomada da totalidade. Isto é, exige apreender a realidade social e nela agir como um complexo, um todo que é tecido junto. Impõe uma perspectiva que integre, organize e totalize (Nogueira, 2001, p.35).

Os objetos têm fronteiras cada vez menos definidas; são constituídos por anéis que se entrecruzam em teias complexas com os dos restantes objetos, a tal ponto que os objetos em si são menos reais que as relações entre eles. (Santos, 2000, 73)

\section{Tecnologias, relações face a face e articulação.}

Agir em redes multi-institucionais altera radicalmente a arquitetura da gestão pública tradicional:

- Derruba as fronteiras da setorialização da ação pública e reforça uma nova tendência: a da emergência de programas-rede que agregam diversos serviços, projetos, sujeitos e organizações no âmbito do território.

- Introduz nova cultura política no fazer social público, que se caracteriza por: socializar o poder, negociar, trabalhar com autonomias, flexibilizar, compatibilizar tempos heterogêneos e múltiplos dos atores e processos de ação.

- Participação, articulação, integração, complementaridade, cooperação e parcerias são conceitos chaves na ação em rede. Por isso mesmo, aumenta a ênfase em processos de circulação e socialização de informações e conhecimentos.

- Exige a definição de eficazes fluxos de circulação no relacionamento de serviços e programas.

- As novas demandas de gestão assentada em redes também alteram o modo de atuação dos profissionais da 
ação pública. Há novas habilidades e competências em discussão - competência comunicativa e relacional, competência articuladora - assentadas em um olhar multidimensional, multisetorial, transdisciplinar.

As Tecnologias de Informação e Comunicação (TICS) constituem-se em um elemento importante na circulação de informações e interatividade entre os sujeitos e instituições que integram as redes. Elas se agregam às relações face a face dos sujeitos, portanto não as substituem, mas as modificam. Antecedem, precedem, sucedem e mantém as relações, criando memória e identidade.

A articulação, outro elemento indispensável ao trabalho social em rede, costura a oferta de oportunidades e de acesso a serviços e relações no território; conjuga e integra a população-alvo a uma cadeia de programas e serviços ligados entre si.

Uma ação de formação com juventudes exige articulação e forte investimento na comunicação e planejamento de ações conjuntas, além de requerer um esforço por parte de cada um dos parceiros em compartilhar princípios e objetivos comuns, agregando valor e agilizando as diversas ações desenvolvidas num programa movido em rede. É uma ação que toma direção agregadora e retotalizante do social, para produzir desenvolvimento, pertencimento e emancipação.

A ação interprogramas, intersetorial, interdisciplinar permite potencializar o agir porque retira cada ação do seu isolamento e assegura uma intervenção agregadora e includente.

Para mobilizar e agir em parceria é necessário:

- Reconhecer que a participação dos diversos atores é o que garante adesão, cor, identidade e legitimidade às ações implementadas.

- Favorecer e assegurar co-autoria com o poder público e demais parceiros.

- Proporcionar a continuidade das ações. A persistência e o investimento técnico e político de longo prazo criam condições de sustentabilidade para as ações em parceria. Esse fator é talvez um dos maiores responsáveis por uma ação compartilhada e exitosa nas intenções e utopias postas em movimento.

- Promover contínua socialização de conhecimentos, sistematizando o conhecimento produzido e investindo na estratégia de sua disseminação. Dessa forma, transforma a reflexão teórico-prática em ferramentas e metodologias que tenham sentido e significado na prática social.
- Manter conduta institucional de mútua cooperação e partilhamento com outras organizações e redes de projetos. Deve-se investir na ação em parceria com organizações governamentais e não-governamentais, fundações empresariais e comunidades locais, na perspectiva de construir participação, mobilizar vontades, implementar pactos de complementaridade entre atores sociais, organizações, projetos e serviços. Ao mesmo tempo, é preciso reconhecer o papel regulador do Estado e fortalecer sua condição de intelligentsia do fazer social público.

- Estabelecer parcerias entre público-privado. Para isso, exige-se, no mundo atual, reconceitualização, já que essa relação costuma vir contaminada pelo receituário neoliberal e, em conseqüência, pode gerar desconfianças sobre seu possível efeito desresponsabilizador da ação do Estado.

- Realizar projetos com parcerias externas. Porém, isso só ganha cor e identidade local, quando redesenhados com a participação de seus atores principais.

A adoção de programas-rede, permitindo a construção de lógicas combinatórias interpolíticas setoriais, programas e instituições de natureza diferenciada, favorece ao grupo juvenil escolhas múltiplas e desenvolvimento integral.

Uma rede dispara outras redes. No programa Jovens Urbanos, parcerias iniciais para o conjunto do programa resultaram em novas parcerias na base.

\section{NOTAS}

Dupas, em seu livro Tensões contemporâneas entre o público e o privado, acrescenta que "num mundo totalmente estruturado em redes (networks) pelas tecnologias da informação, a vida social contemporânea passa a ser composta por uma infinidade de encontros e conexões temporárias. 0 projeto é a ocasião única e o pretexto da conexão; os indivíduos que não têm projetos e não exploram as conexões da rede estão ameaçados de exclusão permanente, já que a metáfora de rede torna-se progressivamente a nova representação da sociedade".

\section{REFERÊNCIAS}

CARDOSO, Ruth. A construção de um novo diálogo. In Gestão de Projetos Sociais.

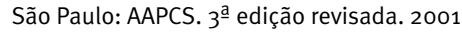

CASTELLS, Manuel. A sociedade em rede (A era da informação: economia, sociedade e cultura; Volume 1, São Paulo: Editora Paz e Terra, 2a. ed., 1999. DUPAS, Gilberto - Tensões contemporâneas entre o público e o privado São Paulo: Paz e Terra, 2003

NOGUEIRA, Marco Aurélio. Em defesa da política. São Paulo: Editora Senac, 2001 SANTOS, Boaventura de Sousa. A Crítica da Razão Indolente: contra o desperdício da experiência. São Paulo: Cortez, Vol 1, 2000. 


\section{PARCERIAS DO PROGRAMA JOVENS URBANOS}

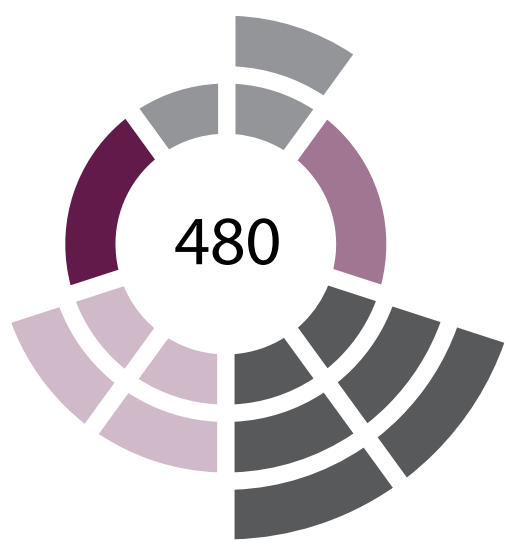

1 EDIÇÃO SÃO PAULO

JOVENS PARTICIPANTES

480 jovens

\section{COOPERAÇÃO TÉCNICO FINANCEIRA}

ICE - Instituto de Cidadania Empresarial

PARCERIAS INSTITUCIONAIS

Secretaria Municipal da Assistência Social

Secretaria Estadual de Assistência e Desenvolvimento Social e PRODESP

IBEAC - Instituto Brasileiro de Estudos e Apoios Comunitários

\section{PARCERIAS TECNOLOGICAS}

Embrapa - Empresa Brasileira de Pesquisa Agropecuária

ONGS EXECUTORAS ZONA SUL

ACB - Associação Beneficente Provisão

Associação Comunitária Monte Azul

Associação de Moradores Jd. Rosana

Serviço Social Bom Jesus

Turma de Touca

ICE - Projeto Casulo

\section{ONGS EXECUTORAS ZONA NORTE}

Ação Comunitária Todos os Irmãos

Assoc. de Moradores Vale Verde

Assoc. Cultural e Desportiva Bandeirantes

Creche Nova Esperança Amigos de Pianoro

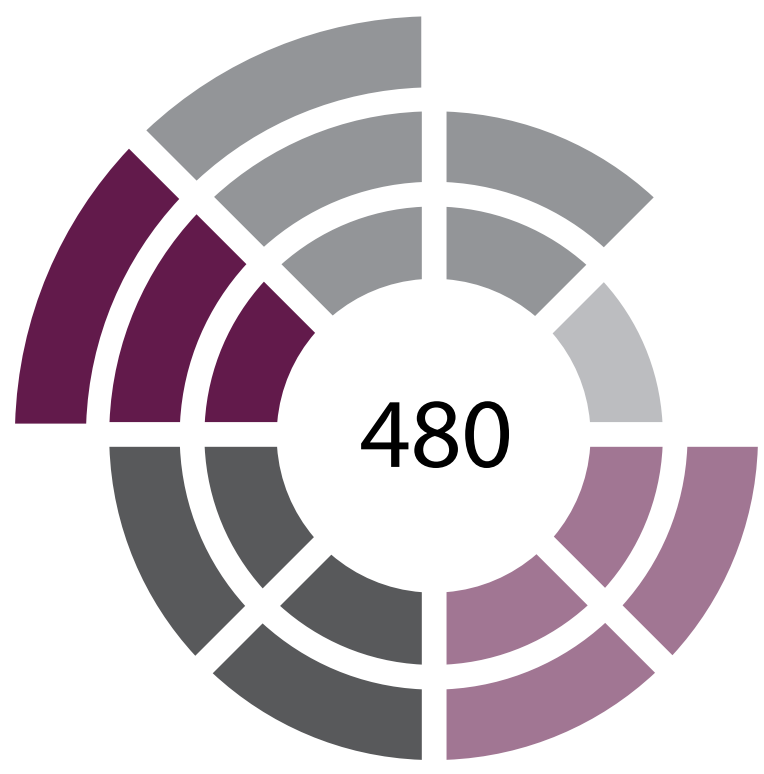

$2^{2}$ EDIÇÃO SÃO PAULO

JOVENS PARTICIPANTES

480 jovens

PARCERIAS INSTITUCIONAIS

Secretaria Municipal da Assistência Social

Secretaria Estadual de Assistência e Desenvolvimento Social e PRODESP

Secretaria Municipal do Trabalho

PARCERIAS TECNOLOGICAS

SABESP

Séc. Municipal do Verde e do Meio Ambiente

Escola da Cidade

Tv Cultura

Embrapa - Empresa Brasileira de Pesquisa Agropecuária

REDE DE APOIO

Cursinho da Poli

ONGS EXECUTORAS ZONA SUL

ACB - Associação Beneficente Provisão

Associação Comunitária Monte Azul

Serviço Social Bom Jesus

ICE - Projeto Casulo

ONGS EXECUTORAS ZONA LESTE

Ação Comunitária Todos os Irmãos

Assoc. de Moradores Vale Verde

Assoc. Cultural e Desportiva Bandeirantes

Creche Nova Esperança Amigos de Pianoro 
3므릉 SÃO PAULO 480 jovens JOVENS PARTICIPANTES

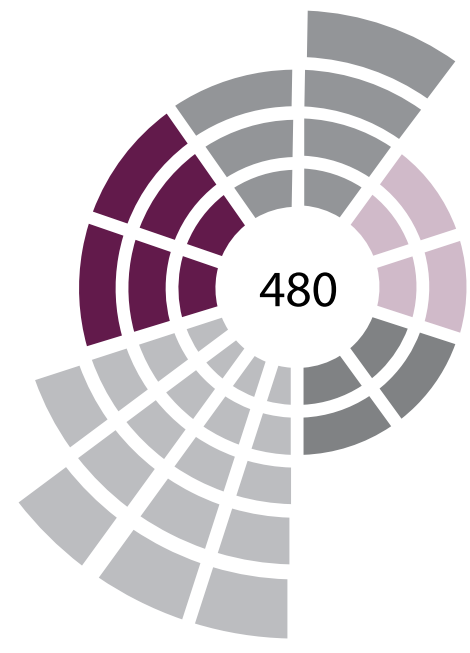

- PARCERIAS INSTITUCIONAIS

SEADS - Secretaria Estadual da Assistência e Desenvolvimento Social SMTrab - Secretaria Municipal do Trabalho da Cidade de São Paulo SME - Secretaria Municipal de Educação/ CEUs da Cidade de São Paulo Subprefeitura Guaianases

Subprefeitura Capela do Socorro Instituto Sou da Paz

PARCERIAS TECNOLOGICAS

Instituto Tomie Ohtake

Centro Universitário Maria Antônia/ USP

Cidade Escola Aprendiz

Fundação Padre Anchieta - Rede Cultura de Televisão

Instituto Criar

ISA - Instituto Socioambiental

CPC - Centro de Preservação Cultural/ USP

ONGS EXECUTORAS ZONA SUL

Comunidade Nova Civilização (Comunidade Cidadã)

Sociedade Comunitária do Jardim Monte Verde

União dos Moradores da Comunidade Sete de Setembro

Projeto de Vento em Popa

ONGS EXECUTORAS ZONA LESTE

Associação de Voluntários Integrados no Brasil (AVIB)

Ação Social Comunitária do Lajeado Joilson de Jesus (Casa dos Meninos) Comunidade Kolping São Francisco de Guaianases

Plugados na Educação

- ASSESSORES TECNOLOGICOS

PROFISSIONAL E EXPERIMENTAÇÃO OFERECIDA

Alexandre Perocca - JOVENS URBANOS TEM MODA

Anderson Rei/ Guilherme - LAMBE LAMBE

Carla Tennenbaum - ORA- OFICINA DE REVALORAÇÃO ARTíSTICA DO GRAJAÚ

Carolina Nakagawa - COMUNIQUE

César Negro - NÓS NA CENA

Clarice Clara - MÍDIA URBANA

Conrado Augusto - GIRAMUNDO

Diego Itu / Carlos Souza - AGRICULTURA URBANA

Ivy Silva - VIVENCIAS SOCIOAMBIENTAIS

José Machado - DESIGN MARCINEIRO

Marisa Martins - RECREOTECA

Nizinga - CAPOEIRA ANGOLA

Paula Autran - LITERATURA EM AÇÃO

Marcio greyk - MOVIMENTO URBANO

Tomás - VIVENCIAS DE TRADIÇÕES PAULISTAS

Waldir Hernandes - ESPAÇO URBANO

Meta Ambiental - ÁGUA, LIXO E TECNOLOGIAS LIMPAS

Novolhar - OFICINA DE VÍDEO

Midiativa MOSTRA DE TV DE QUALIDADE PARA CRIANÇAS

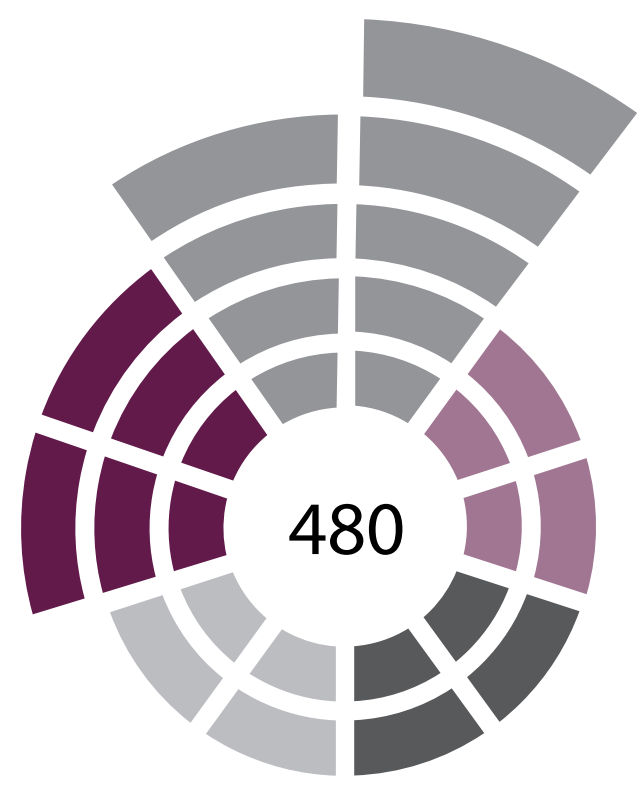

1 a EDIÇÃO RIO DE JANEIRO

JOVENS PARTICIPANTES

480 jovens

\section{- PARCERIAS EXECUTIVAS}

PCRJ-SMAS / RJ (Secretaria Municipal de Assistência Social do Rio de Janeiro)

FIOCRUZ (Fundação Oswaldo Cruz)

Canal Futura

PARCERIAS TECNOLOGICAS

Secretaria Municipal de Esporte e Lazer - SMEL

FIOCRUZ (Fundação Oswaldo Cruz)

Canal Futura / Geração Futura

Canal Futura / Nós do Morro

TVE / Rádio MEC

CIEZO - Conselho das Instituições de Ensino Superior da Zona

Oeste

Observatório de Favelas

Spectaculu Kabum

CECIP (Centro de Criação de Imagem Popular)

\section{REDE DE APOIO}

Secretaria Municipal de Educação

Secretaria Estadual de Educação

UFRJ - PACC

ESPRO

ONGS EXECUTORAS ZONA NORTE

UADEMA

Rede CCAP

Ação Alternativa

Ass. Família Saúde e Cidadania

ONGS EXECUTORAS ZONA OESTE

CAMPO

CIEZO

ACAPS

São Cipriano 